\title{
Research and Design of Virtualization Multimedia Teaching Platform Based on Cloud Computing
}

\author{
Chen Guang-qun \\ Nanchang Teachers College
}

\begin{abstract}
In the context of cloud computing, it is urgent to update the teaching facilities in colleges and universities so as to provide more convenient and advanced teaching platform for teachers and therefore the construction of multimedia teaching platform is pressing. This paper researches on the multimedia teaching platform based on advanced virtualization in the context of cloud computing.
\end{abstract}

KeyWords-Cloud Computing; Big Data; Virtualization

\section{INTRODUCTION}

When internet technology emerges, a popular name of internet is cloud and therefore a new calculation method based on internet is called cloud computing. Cloud computing is a kind of calculation based on internet among which the software and information resources sharing is distributed to computer and equipment according to needs. The development trend of education development informationization asks to establish an effective, safe, and highly available data center network infrastructure so as to help IT managerial personnel get rid of replicate IT operation maintenance and then pay attention to business support and innovation. So, it is easy for parent business to issue and update universal application while subordinate department will find it easy to choose satisfactory individual needs as well as innovation, considering both characteristics and unity. The cloud computing and virtualization can help to realize the comb and optimization of information resources to share the resources in cloud computing. In order to satisfy this requirement, school data center has to establish a virtual platform which is easy to manage-the vSphere with Operations Management platform.

Therefore, Professor Liu Peng, a well-known Chinese computer expert gives a definition which is widely accepted, 'Cloud computing is able to provide expandable distributed computing with low cost via internet'. Besides, cloud computing can provide expandable and dynamic internet resources as well as service resources for customers by virtualization pre-customized service agreement.

It is divided into the following steps: first, provide quantitative computing resources to customers based on specific interface via internet; second, scatter resources and find out the minimum measuring unit and then gather together to re-allocate; third, put all local affairs in the cloud and carry out calculation is so-called cloud computing.

\section{ADVANCED VIRTUALIZATION PLAN}

The previous plan is good which faces the common area and the architecture design is too bloated. In order to face special teaching management, the platform is advanced and simplified to improve the performance, showing in Fig .1. 


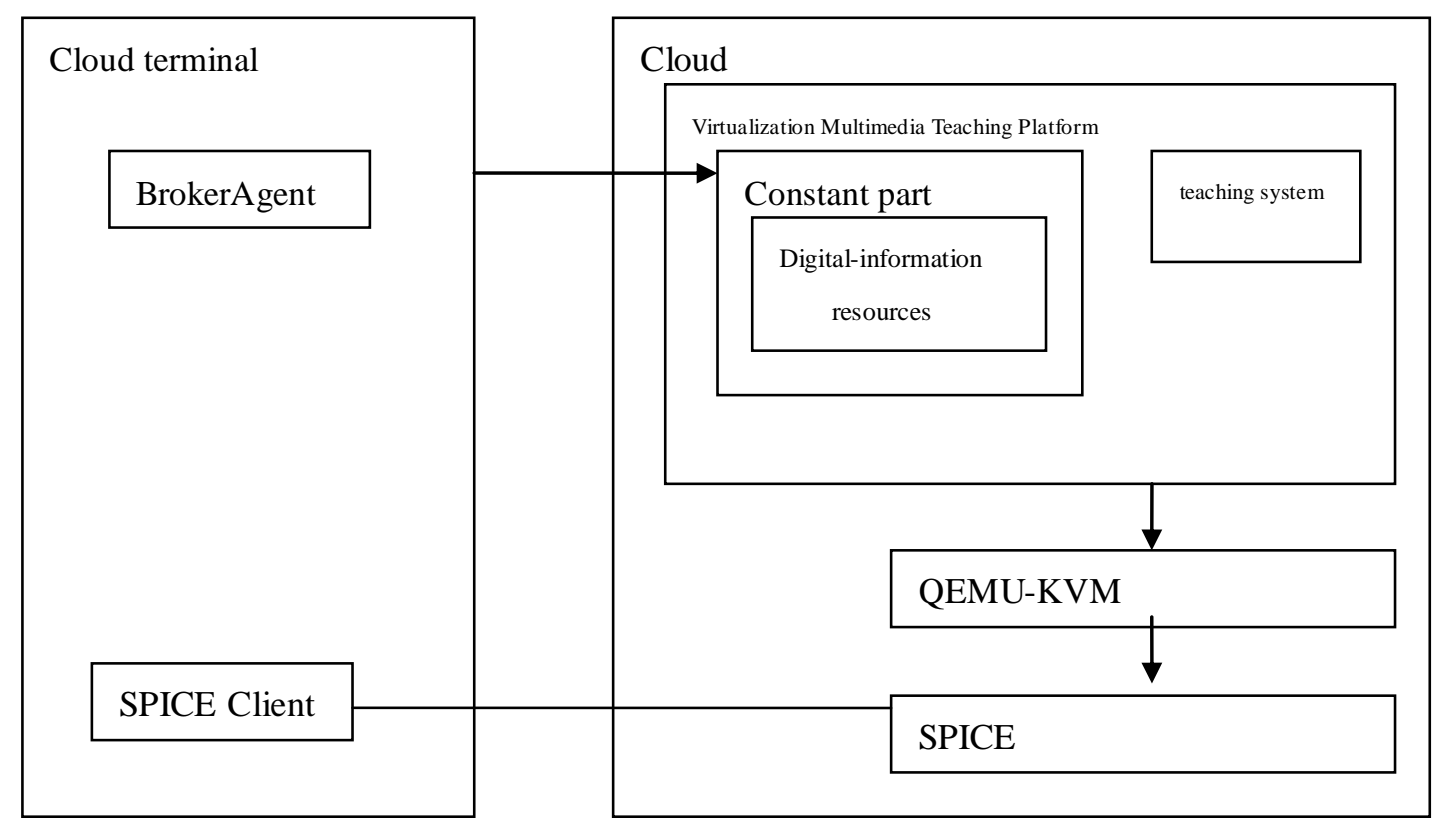

Figure 1. Framework Program facing specific education field

Showing in Fig .1. the previous common framework is made up of three parts, which are Server, Broker and Cloud Terminal. After integration, the GuestAgent module of original server and HostAgent interface module of Broker are eliminated because they originally connects Broker and server while after combination of two sub-systems these two modules are not required. Then, the Libvirt module of the original server is eliminated because it can be deemed as open source virtual environments sets with differences which can shield virtualization, including complete API function controlling different host machines. This paper is not targeted at the common area and therefore only few API functions will be adopted if necessary and a whole and complete virtual environments set is not required.

After eliminating extra modules, the cloud still keeps QEMU-KVM module as well as SPIECE server module, among which QEMU-KVM module realizes the CPU virtualization, virtualizing memory and $\mathrm{I} / 0$ simulate operation so as to establish the virtual environment. Besides, SPIECE server realizes desk-top data transmission as well as roaming effect among clouds.

Meanwhile, a message management application system should be innovated in the cloud, which on the one hand simplifies virtual machine management, server manager, cloud terminal management, user management, database management functions of Broker and organically integrate the them as constant parts and on the other hand take the teaching module as changeable part to carry out secondary development.

Concerning the cloud terminal, the configure module should be eliminated because this paper is not targeted at common area but specific area and diverse settings are not necessary and only one fixed setting is enough in specific environment. Then, the BrokerAgent module as well as SPICE customer module can be kept, among which BrokerAgent module is responsible to connect the communication among clouds rather than connecting Broler, including virtual machine connecting, user login etc while SPICE module is responsible to receive the information of SPICE server.

Then, the desk-top virtual framework is completely altered which cannot only satisfy the requirement of desk-top virtualization but also integrate specific business with multi-media teaching to improve the performance and optimize the effect. The most important point is the multi-media teaching management system based on cloud. In the next chapter, the requirement, design, realization and testing of this system are described.

\section{MULTI-MEDIA TEACHING PLATFORM DESIGN}

Teachers can publish video in multimedia teaching system while students can carry out remote studying in this system. Besides, teachers can send message to students and computer so as to make students know the operation through computer screening. 


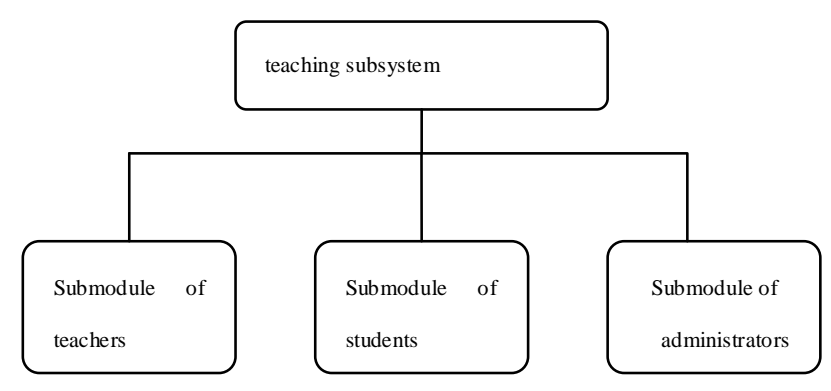

Figure 2. Multi-media teaching subsystem

\section{A. Analysis on the submodule of teachers}

It is responsible to release teaching resources and information, lead students to complete studying; deliver information, organize exam, give online assignment and correct errors, answer various questions of teachers etc so as to convey the information to teachers and students based on the voice of teachers in the computer. Besides, students can see how teachers operate via this window while the server is able to save files by recording animation and spread it to other teachers and students for learning.

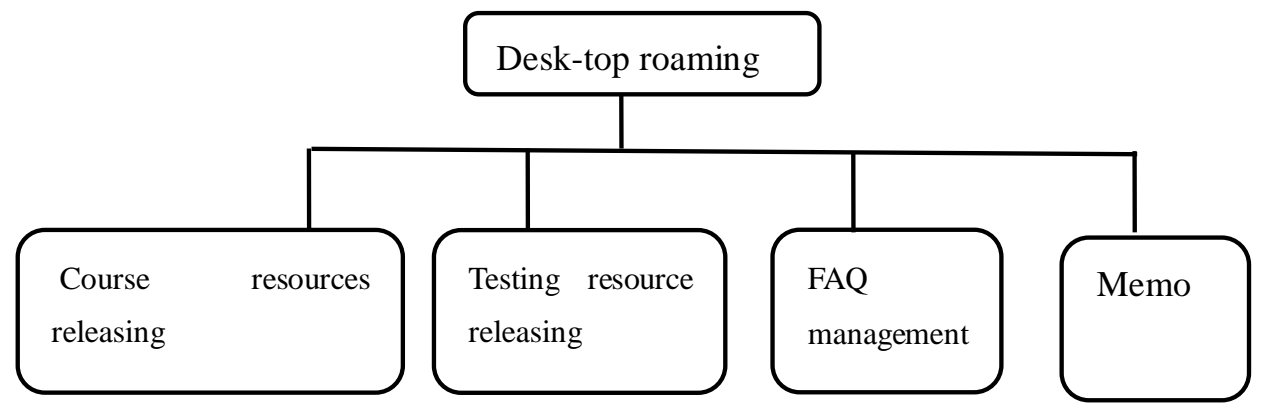

Figure 3. Analysis on the submodule of teachers

\section{B. Analysis on the submodule of students}

It can help to realize online studying and students can submit assignment online while teachers can correct students' papers and interact with students showing in Fig .5.

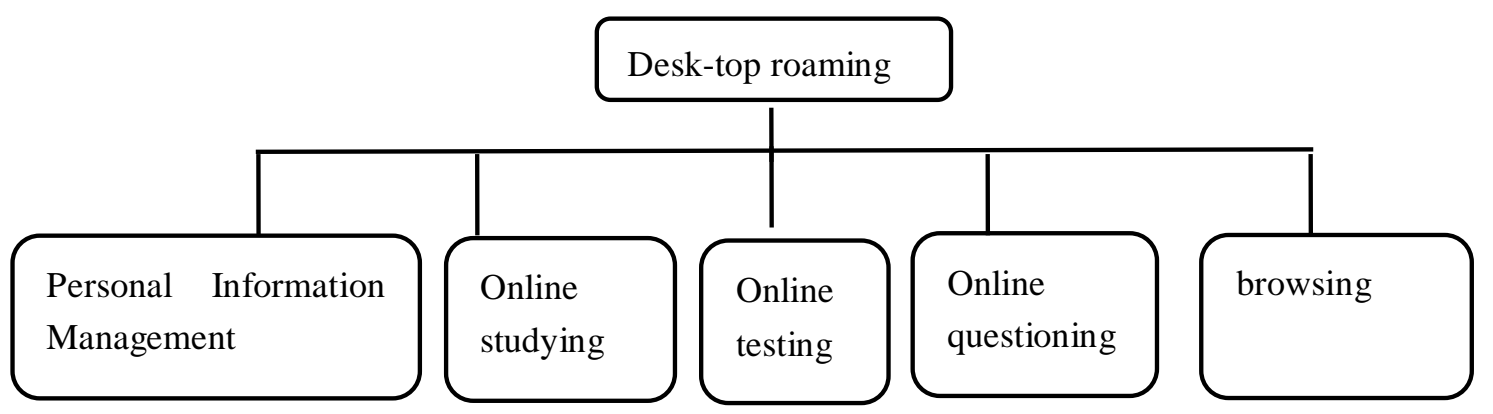

Figure 4. Analysis on the submodule of students 

various roles in the teaching platform, and should also collect data, analyze and store data, showing in Fig .5.

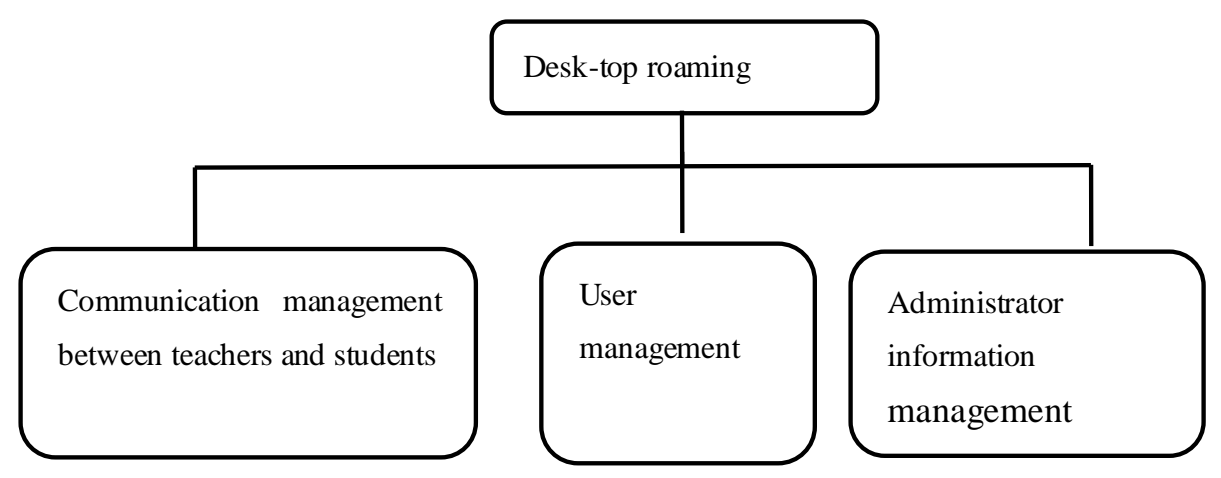

Figure 5. Analysis on the submodule of administrator

\section{ANALYSIS ON THE NON-FUNCTIONAL} REQUIREMENT

\section{A. Desynchrony of teacher office scene and multi-media information}

At present, traditional teacher computer adopts PC which is equipped with hardware operating system in the bottom and all data is stored in the local disk and webmaster assumes the responsibility to maintain and manage the PC.

Common problems include: server operation systems should be frequently updated with high cost and multiple requirements yet limited access.

\section{B. Classroom scene}

At present, students are arranged in common classrooms for daily studying and traditional teachers adopt PC and carry out management and maintenance based on restore card. What's more, teachers take USB flash disk or sharable network courseware to teach. What's more, the current teacher computers have following features: complicated daily management as well as maintenance, poor compatibility, easy to break and update not in time.

\section{OPERATION AND MAINTENANCE SCENE}

In traditional distributed PC computing module if one machine has problems, IT management and maintenance personnel has to come to the site o repair.

In terms of management and maintenance approaches, they have following features: both software and hardware will easily have problems, waste teaching time, new teachers have to spend time in understanding the system, inconvenient for moving.

\section{DATABASE MANAGEMENT REQUIREMENT}

The education resources stored in cloud data include user information, resources, information, mobile devices, materials, comments, information and education, application data and other data. User information includes common user data, database administrator user, developers, education specialist, enterprise user etc. The resources information is complicated which cover various education information resources, education information of three major types, online courses and common education. The mobile device information mainly includes mobile device management and registration information of common users. In addition, there is also mobile device visiting loading. The information is a middle evaluation between public cloud and private cloud to provide relevant information resource description. The data storage of education applied procedure is teaching tool which belongs to application program.

\section{CONCLUSION}

This paper firstly introduces relevant knowledge of cloud computing and comes up with advanced virtualization plan to carry out research on the multi-media teaching platform based on it. Besides, it also study on the database design from the perspective of teachers, students, system management and maintenance etc.

\section{REFERENCES}

[1] Wang Bin. Discussion on the development and key technology of cloud computing[J]. Electronic Test. 2015(11)

[2] Xu Jun, Tang Lianzhang. Exploration and practice of informatization education in the era of cloud computing and big data- Guangdong education cloud plan and demonstration project progress $[\mathrm{J}]$. Educational Information Technology. 2014(11)

[3]. Li Wei. Multi-media system framework based on virtualization in colleges and universities [J]. Journal of Baoji College of Arts and Science (natural science edition). 2013 (02)

[4] El Ahrache,S.I,Badir,H,Tabaa,Y.et al.Massive Open Online Courses: A New Dawn for Higher Education?. International Journal on Computer Science and Engineering . 2013

[5] Vedant Godhamgaonkar,Anuja Lakhote,Y. B. Gurav.Integral System for Automation of Education Board and IT Association using Cloud and Mobilink. International Journal on Computer Science and Engineering . 2013 